\title{
Commentary: Combining Ecosystem and Single-Species Modeling to Provide Ecosystem-Based Fisheries Management Advice Within Current Management Systems
}

\author{
Robert B. Thorpe*, Michael A. Spence, Paul J. Dolder and Richard D. M. Nash \\ Centre for Environment, Fisheries and Aquaculture Science (CEFAS), Lowestoft, United Kingdom
}

Keywords: stock assessment, ecosystem, advice, single species and multiple fisheries, multispecies models

\section{A Commentary on}

OPEN ACCESS

Edited by:

Michael Arthur St. John, Technical University of

Denmark, Denmark

Reviewed by:

Daniel S. Holland,

National Oceanic and Atmospheric Administration (NOAA), United States

Andre Eric Punt,

University of Washington,

United States

*Correspondence:

Robert B. Thorpe

robert.thorpe@cefas.co.uk

Specialty section:

This article was submitted to Marine Ecosystem Ecology,

a section of the journal

Frontiers in Marine Science

Received: 10 May 2021 Accepted: 16 September 2021

Published: 07 October 2021

Citation:

Thorpe RB, Spence MA, Dolder PJ and Nash RDM (2021) Commentary: Combining Ecosystem and Single-Species Modeling to Provide

Ecosystem-Based Fisheries

Management Advice Within Current

Management Systems.

Front. Mar. Sci. 8:707841

doi: 10.3389/fmars.2021.707841
Combining Ecosystem and Single-Species Modeling to Provide Ecosystem-Based Fisheries Management Advice Within Current Management Systems

by Howell, D., Schueller, A. M., Bentley, J. W., Buchheister, A., Chagaris, D., Cieri, M., Drew, K., Lundy, M. G., Pedreschi, D., Reid, D. G., and Townsend, H. (2021). Front. Mar. Sci. 7:607831. doi: 10.3389/fmars.2020.607831

\section{INTRODUCTION}

Although legislation mandates a holistic approach, and many countries have formally committed to Ecosystem-Based Fisheries Management (EBFM), progress toward this has been slow. There are many reasons for this, one being simple inertia; a reluctance to throw away the important management insights provided by the current focus on single species methods. This timely paper proposes an incremental approach, where single species assessments continue to be used, subject to adjustment on the basis of wider ecosystem considerations. Two case studies are presented, (a) Atlantic menhaden Brevoortia tyrannus, where quotas are adjusted downwards to ensure that there is enough food for predators, and (b) the Irish Sea, where the ICES "Pretty Good Yield" (PGY) ranges that were originally designed to allow flexibility in the operation of the mixed fishery can be re-purposed to serve as ranges for ecosystem status, with fishing being near the top of the ranges if conditions are forecast to be favorable, and near the bottom if not. The approach has the advantage of allowing ecosystem state to directly influence quota-setting, without jettisoning any of the existing machinery, and its applicability is showcased in these two case studies.

We believe this pragmatic approach is a valuable step forward. The involvement of stakeholders throughout the process in both case studies is particularly important, especially as the approach of Howell et al. (2021) focusses on biological reference points and risk, leaving the important trade-offs against socio-economic impacts (employment, security of income streams, and cultural factorsCaswell et al., 2020) to be addressed by other means. However, the approach as formulated in the second (Irish Sea) study makes three related assumptions that are unlikely to be true in practice, namely (i) that the ecosystem model [in this case Ecopath (Bentley et al., 2019), though it would apply equally to any other model] correctly determines the true status of the ecosystem, or at the very least its failure to do so is not reinforced by interaction with the single species models so it becomes material, (ii) that fishing rates are directly translatable between different models (see Spence et al., 2021 for a discussion of this), and (iii) that the pre-calculated single-species 
TABLE 1 | Incorporating ecosystem considerations into the advisory process.

\begin{tabular}{|c|c|c|}
\hline Issue: & Consequence & Remedy \\
\hline $\begin{array}{l}\text { Ecosystem model-data } \\
\text { discrepancy is } \\
\text { significant or becomes } \\
\text { significant when } \\
\text { interacting with } \\
\text { discrepancies in the } \\
\text { single species models. }\end{array}$ & $\begin{array}{l}\text { Failure to identify } \\
\text { current state of } \\
\text { ecosystem, leading to } \\
\text { wrong advice. }\end{array}$ & $\begin{array}{l}\text { Need to consider } \\
\text { discrepancy between } \\
\text { ecosystem model and } \\
\text { observations as part of } \\
\text { advice framework } \\
\text { (Kennedy and } \\
\text { O'Hagan, 2001; } \\
\text { Spence et al., 2018). }\end{array}$ \\
\hline $\begin{array}{l}\text { Model-dependency of } \\
\text { fishing rates (Brooks } \\
\text { and Deroba, 2015; } \\
\text { Spence et al., 2021) }\end{array}$ & $\begin{array}{l}\text { Management to wrong } \\
\text { state even if the current } \\
\text { one correctly identified. }\end{array}$ & \\
\hline $\begin{array}{l}\text { Distribution of risk not } \\
\text { equivalent across PGY } \\
\text { ranges (Thorpe et al., } \\
\text { 2017). }\end{array}$ & $\begin{array}{l}\text { Targets may not be } \\
\text { precautionary when } \\
\text { considered together } \\
\text { even if we have the } \\
\text { right state and fishing } \\
\text { rates are transferrable } \\
\text { between models. }\end{array}$ & $\begin{array}{l}\text { Compare risk of } \\
\text { depletion at } \\
\text { recommended target } \\
\text { Fs with other parts of } \\
\text { PGY range space in } \\
\text { ecosystem model. }\end{array}$ \\
\hline
\end{tabular}

precautionary limits remain valid; that there is an equivalence of precautionarity throughout the pre-determined PGY ranges, whereas in reality this is not the case because the ranges are estimated on the basis of single species assessments, whereas the community response is inherently multispecies (Thorpe et al., 2017; Thorpe and De Oliveira, 2019). Whilst the first two assumptions also apply in the case of Atlantic menhaden, the less complex nature of the fishery may reduce the risk of mismanagement due to incorrect attribution of state or inconsistent specification of fishing rates.

As a consequence of the above three assumptions when using PGY ranges, we may fail to correctly characterize the state of the ecosystem, manage to the wrong state though the use of incommensurate fishing rates between models even if we have identified the right state, or underestimate risks even if we have identified the right state and we are lucky enough that the fishing rates happen to be transferrable between the models in practice. Therefore, we propose one additional facet for the process, whereby model-data discrepancies for the models are calculated (Kennedy and O'Hagan, 2001; Spence et al., 2018), to enable a consistent description of state across models. Evaluation of alternative places in the PGY yield space can also be carried out as per the discussion to ensure that risks remain acceptable across the community (Table 1).

\section{DISCUSSION}

For the Irish Sea study, outcomes were recommendations for target Fs within the PGY ranges that have been adopted for many EU managed stocks. ICES provides precautionary $F_{M S Y}$ ranges ( $F_{M S Y \text { upper }}$ and $\left.F_{\text {MSYlower }}\right)$ that are derived to deliver no more than a $5 \%$ reduction in long-term yield compared with MSY for selected stocks (Hilborn, 2010; ICES, 2016; Rindorf et al., 2017). Using the identified indicator for each stock, the $F_{\text {target }}$ value was scaled linearly within the range ( $F_{M S Y l o w e r}$, $\left.F_{M S Y u p p e r}\right)$ according to the current value of the indicator within the historical range during the model tuning period. For example, if the indicator identified for a particular stock was $80 \%$ of the way to the most favorable value observed over the model period, then $F_{\text {target }}$ was adjusted to $80 \%$ of the way to the higher $F_{M S Y \text { upper }}$ value. However, these ranges are independently constructed from single-species perspective, and it seems reasonable to suppose that fishing all stocks at the bottom of their ranges will have quite a different risk profile from fishing all of them at the top of their ranges, or fishing forage fish at the top of their ranges and their predators at the bottom. Thorpe et al. (2017) investigated this issue for a 21-stock North Sea fish community. By using a Nash Equilibrium (Farcas and Rossberg, 2016; Norrstrom et al., 2017) to define multispecies MSY, they were able to construct analogous "pretty good yield" ranges for all stocks simultaneously, and show that the risk/reward profile was quite different across this space (their Figures 4, 6). Risk reward ratios could vary by almost a factor of 3 (their Table 2) whilst the sum of individually precautionary Fs was not always precautionary. Whilst these scenarios assumed a constant environment, and Howell et al. (2021) only propose fishing near the top of ranges if ecosystem indicators are favorable, the risks increase so markedly through the ranges that it seems prudent to carry out a further check of the combined effect of the tweaked rates on outcomes (a) within the ecosystem model, and (b) sensitivity studies using the single species assessments bounded by different estimates of natural mortality based on the response of the ecosystem model. An alternative would be the pro-active implementation of harvest control rules through management strategy evaluation, which has been shown to significantly reduce risks (see Thorpe and De Oliveira, 2019). This additional step, alongside consideration of model-data discrepancies will increase the robustness of the novel fusion of single species and multispecies that Howell et al. (2021) propose, and enhance its considerable utility to management.

\section{AUTHOR CONTRIBUTIONS}

RT initiated the idea of a commentary. All authors contributed to the drafting and review of the manuscript.

\section{ACKNOWLEDGMENTS}

We are grateful to the Department of Environment, Food, and Rural Affairs (DEFRA) and the PANDORA EU H2020 project for providing funding. 


\section{REFERENCES}

Bentley, J., Serpetti, N., Fox, C. J., Reid, D. G., and Heymans, J. J. (2019). Modelling the Food Web in the Irish Sea in the Context of a Depleted Commercial Fish Community. Part 2; ICES Ecopath With Ecosim Key Run. Oban: Scottish Association for Marine Science Report 297. doi: 10.13140/RG.2.2.15136.12809

Brooks, E., and Deroba, J. J. (2015). When "data" are not data: the pitfalls of posthoc analyses that use stock assessment model output. Can. J. Fish. Aquatic Sci. 72, 1-8. doi: 10.1139/cjfas-2014-0231

Caswell, B. A., Klein, E. S., Alleway, H. K., Ball, J. E., Botero, J., Cardinale, M., et al. (2020). Something old, something new: historical perspectives provide lessons for blue growth agendas. Fish Fisheries 21, 774-796. doi: 10.1111/faf.12460

Farcas, A., and Rossberg, A. G. (2016). Maximum sustainable yield from interacting fish stocks in an uncertain world: two policy choices and underlying trade-offs. ICES J. Marine Sci. 73, 2499-2508. doi: 10.1093/icesjms/fsw113

Hilborn, R. (2010). Pretty good yield and exploited fishes. Marine Policy 34, 193-196. doi: 10.1016/j.marpol.2009.04.013

Howell, D., Schueller, A. M., Bentley, J. W., Buchheister, A., Chagaris, D., Cieri, M., et al. (2021). Combining ecosystem and single-species modeling to provide ecosystem-based fisheries management advice within current management Systems. Front. Mar. Sci. 7:607831. doi: 10.3389/fmars.2020.607831

ICES (2016). EU Request to ICES to Provide FMSY Ranges for Selected Stocks in ICES Subareas 5 to 10. Available online at: https://www.ices.dk/sites/pub/ Publication\%20Reports/Advice/2016/Special_Requests/EU_FMSY_ranges_ for_selected_Western_Waters_Stocks.pdf (accessed February 5, 2016).

Kennedy, M. C., and O'Hagan, A. (2001). Bayesian calibration of computer models. J. R. Statistical Soc. 63, 425-464. doi: 10.1111/1467-9868.00294

Norrstrom, N., Casini, M., and Holmgren, N. M. A. (2017). Nash equilibrium can resolve conflicting maximum sustainable yields in multi-species fisheries management. ICES Journal of Marine Science 74:78-90.

Rindorf, A., Dichmont, C. M., Levin, P. S., Mace, P., Pascoe, S., Prellezo, R., et al. (2017). Food for thought: pretty good multispecies yield. ICES J. Marine Sci. 74, 475-486. doi: 10.1093/icesjms/fsw071

Spence, M. A., Blanchard, J. L., Rossberg, A. G., Heath, M. R., Heymans, J. J., Mackinson, S., et al. (2018). A general framework for combining ecosystem models. Fish Fisheries 19, 1031-1042. doi: 10.1111/faf. 12310

Spence, M. A., Thorpe, R. B., Blackwell, P. G., Scott, F., Southwell, R., and Blanchard, J. L. (2021). Quantifying uncertainty and dynamical changes in multi-species fishing mortality rates, catches and biomass by combining state-space and size-based multispecies models. Fish Fisheries. 22, 1-15. doi: $10.1111 /$ faf. 12543

Thorpe, R. B., and De Oliveira, J. A. A. (2019). Comparing conceptual frameworks for a fish community MSY (FCMSY) using management strategy evaluation-an example from the North Sea. ICES J. Marine Sci. 76, 813-823. doi: 10.1093/icesjms/f sz015

Thorpe, R. B., Jennings, S., and Dolder, P. J. (2017). Risks and benefits of catching pretty good yield in multispecies mixed fisheries. ICES J. Marine Sci. 74, 2097-2106. doi: 10.1093/icesjms/f sx062

Conflict of Interest: The authors declare that the research was conducted in the absence of any commercial or financial relationships that could be construed as a potential conflict of interest.

Publisher's Note: All claims expressed in this article are solely those of the authors and do not necessarily represent those of their affiliated organizations, or those of the publisher, the editors and the reviewers. Any product that may be evaluated in this article, or claim that may be made by its manufacturer, is not guaranteed or endorsed by the publisher.

Copyright (c) 2021 Thorpe, Spence, Dolder and Nash. This is an open-access article distributed under the terms of the Creative Commons Attribution License (CC BY). The use, distribution or reproduction in other forums is permitted, provided the original author(s) and the copyright owner(s) are credited and that the original publication in this journal is cited, in accordance with accepted academic practice. No use, distribution or reproduction is permitted which does not comply with these terms. 